\title{
NEW DIRECTIONS WITH DIGITAL ARCHAEOLOGY AND SPATIAL ANALYSIS IN THE JEZREEL VALLEY
}

\author{
Robert S. HOMSHER ${ }^{1}$, MATTHEW J. AdAMS ${ }^{2}$, AdAM B. PRINS ${ }^{3}$, \\ RYAN GARDNER-COOK ${ }^{4}$, YOTAM TEPPER ${ }^{5}$ \\ ${ }^{1}$ Harvard University, Cambridge, USA, e-mail: rhomsher@fas.harvard.edu \\ ${ }^{2}$ W.F. Albright Institute for Archaeological Research, Jerusalem, Israel \\ ${ }^{3}$ Durham University, Durham, UK \\ ${ }^{4}$ Stony Brook University, New York, USA \\ ${ }^{5}$ University of Haifa, Haifa, Israel
}

Received: $1^{\text {st }}$ May 2017, Accepted: $30^{\text {th }}$ December 2017

\begin{abstract}
The Jezreel Valley Regional Project (JVRP) is a long-term multidisciplinary project investigating human activity in the Jezreel Valley through all periods through the modern era. This research incorporates extensive and intensive archaeological survey and excavation at several spatial scales, and utilizes a number of methodological approaches to documentation and spatial analysis. One of the major challenges of this project has been coping with a high volume of data, and integrating cutting-edge technology into our workflow to solve the problems that many archaeologists face. This paper will present an overview of our field-based methods of data acquisition, particularly by means of 3D photogrammetry, remote sensing, and high-precision ground control. When integrated through our data management system and used in GIS applications, these data not only produce plans and imagery far more precise than conventional approaches, but the methods used are incredibly time-efficient, cost-effective, and produce archival digital data. Furthermore, we will report on results of spatial analysis of archaeological activity in the Jezreel Valley in conjunction with digital terrain and hydrological modelling of the landscape. These digital techniques allow us to study human and environmental changes in the landscape like never before.
\end{abstract}

Keywords: Jezreel Valley, Archaeology, Landscape Survey, GIS, Structure from Motion

\section{INTRODUCTION}

During virtually all periods of archaeological interest in the Levant, the Jezreel Valley in modern Israel has been a critically important region for cultural connectivity and agricultural potential. The Jezreel Valley Regional Project (JVRP) was initiated in 2010 as a long-term multidisciplinary project investigating human activity in the Jezreel Valley (Emek Yizra'el, Marj ibn Āmir) through all periods, including the modern era. ${ }^{1}$ This research incorporates

\footnotetext{
${ }^{1}$ The JVRP is directed by Matthew Adams and Robert Homsher, under which multiple collaborative projects are operated. The JVRP's Advanced Regional Survey is conducted under the auspices of the W.F. Albright Institute of Archaeological Research (License No. S-678/2015-16; map ref. 217900-22250/733350-7350), and is directed by Matthew Adams, Robert Homsher, and Yotam Tepper.
} 
extensive and intensive landscape survey and archaeological excavation at several spatial scales, and targeting a diverse array of material evidence ranging from cultural artifacts to environmental data. These data involve a heavy geospatial component, which requires a number of methodological approaches to acquisition, documentation, and spatial analysis. Therefore, one of the project's primary goals is to innovate methods to fully utilize a high volume of data, and integrating cutting-edge technology into our workflow to solve the problems that many archaeologists face.

Here we present an overview of our field-based methods of data acquisition, particularly by means of remote sensing, 3D photogrammetry, and high-precision spatial control. When integrated through our data management system and used in GIS applications, these data not only produce plans and imagery that are far more precise than more conventional approaches, but the methods used are incredibly time-efficient, cost-effective, and produce high quality digital archival datasets. In short, these digital techniques assist us in meeting the challenges of a complex and dynamic landscape with a rich archaeological record.

\section{THE VALLEY AND ITS CHALLENGES}

The Jezreel Valley lies between the Central Highlands to the south and the hills of the Galilee to the north. The valley itself is roughly triangular, surrounded by: (1) the foot of the Nazareth Ridge in the northeast; (2) the low Shefar'am Hills in the northwest; (3) the Carmel Ridge and the Menashe Region to the west; (4) the Iron Hills of Samaria to the south; and (5) the edge of the Gilboa to the east. On its north-western end, the Jezreel Valley is connected to the Northern Coastal Plain by the Zebulon Valley, and its south-eastern end is connected to the Beth Shean Valley and the greater Jordan Valley by the Harod Valley. The elevation in the center of the valley is about $100 \mathrm{~m}$ above sea level, grading to sea level in the west and dropping to $200 \mathrm{~m}$ below sea level in the Beth Shean Valley to the east as it approaches the Jordan Valley. We take a rather maximal approach to defining the extent of the valley as the topographical watershed draining into it, incorporating hillslopes and dynamic terrain that are difficult to define spatially with great precision. The center of the valley is a relatively flat alluvial plain often referred to as the Esdraelon Plain (Fig. 1).

Fig. 1: A digital terrain model (DTM) of the Jezreel Valley

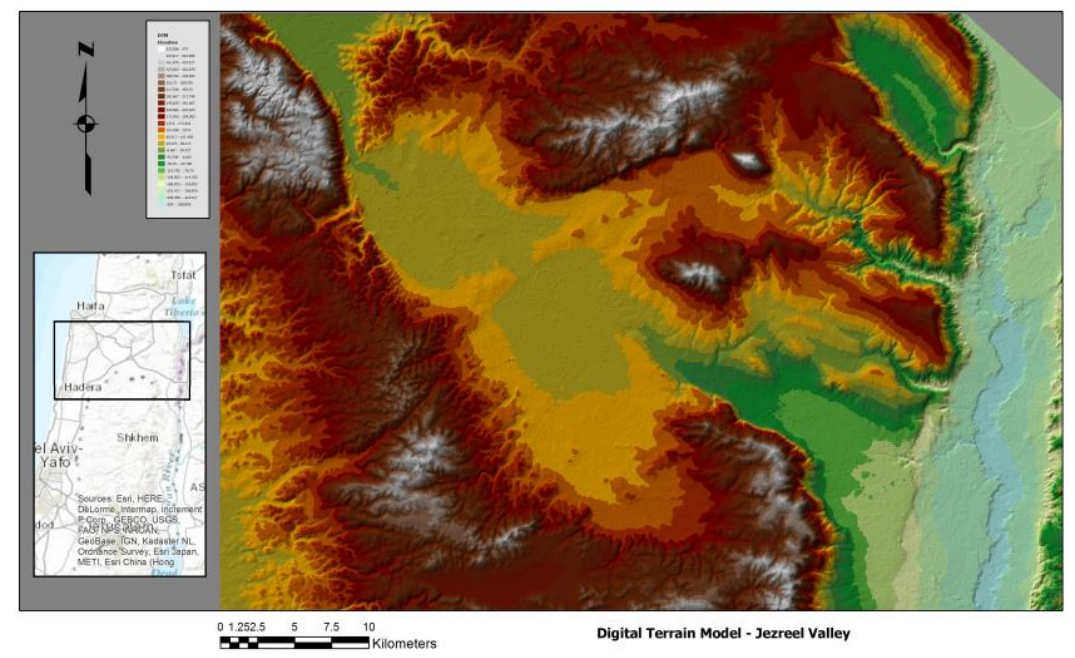


Geologically speaking, the Jezreel Valley is a graben created by parallel faults formed in the Early Pliocene, with a bed of flat morphology consisting of alluvium to a considerable depth (cf. Horowitz, 1979). The predominantly alluvial (and partly colluvial) sediment of the valley is dark, heavy, and rich in organic matter, which is due to the swamps that existed there until the modern era (Orni \& Efrat, 1964). The Qishon Stream runs diagonally (southeast to northwest) through the valley from its source on Mount Gilboa through the gap of the Zebulon Valley unto its mouth in the Haifa Bay. Several springs are distributed throughout the valley margins along geological interfaces. Due to excess water in certain areas, the sediments may be hydromorphic or hal-hydromorphic (Horowitz, 1979).

The dynamic sedimentary geomorphology of the plain during the Holocene has significant implications on detecting archaeological phenomena in the valley due to both erosional and depositional deposits that might bury or transport objects of interest. Moreover, a contemporary archaeologist looking at the valley today will find it difficult enough to reconstruct the landscape prior to major drainage projects and other landscape modifications over just the last century, let alone trying to unravel the long-term changes caused by human-landscape interactions, shifts in climate, and geomorphic processes stretching thousands of years into the past. Thus, when it comes to undertaking regional survey dealing with archaeological remains, spatial patterns of settlement and interaction, or questions of human ecology, we must come to terms with the region's environmental changes over the longue durée, not as an afterthought, but as a starting point for archaeological enquiry.

As part of the JVRP's pilot study of Tel Megiddo East and the Megiddo environs ${ }^{\mathrm{i}}$, both manual and mechanical excavations were carried out that exposed the Holocene sedimentary sequence in the vicinity. In short, our results corroborated a study conducted by Rosen (2006), and are summarized in Fig. 2.

Fig. 2: Schematic geological sections of three representative trenches in the Megiddo environs

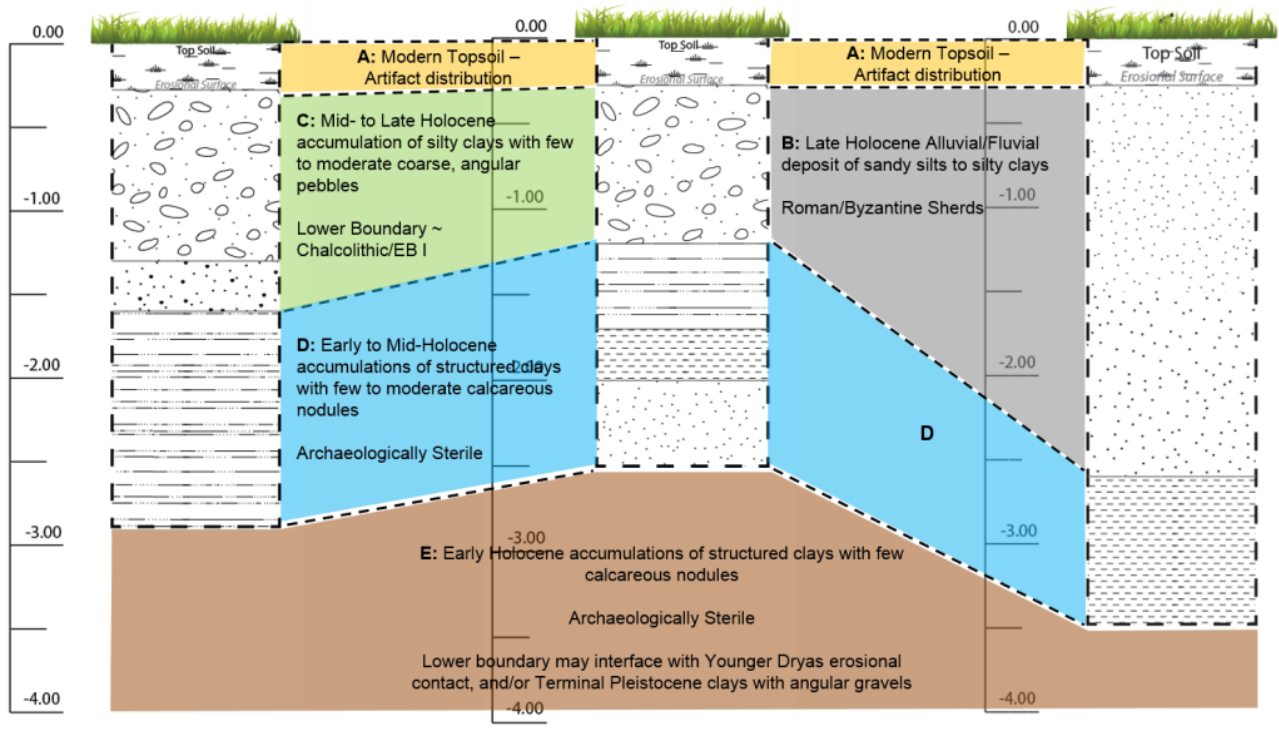

The relevant implications of this work are the following: (1) heavy clays developed over Pleistocene gravels and limestone bedrock during the early- to mid-Holocene due to heavy rain and marshy environments (especially in the western part of the plain); (2) around 5,000 
BP the climate became drier with less rainfall (a regime comparable to today), but quite a lot of water was still present in the valley; and (3) a major colluvial deposit occurred during the late Roman to Byzantine period, possibly resulting from anthropogenic impact on the landscape (e.g., deforestation, large-scale agriculture). The latter episode resulted in the deposition of one or more meters of sediment across the plain, which sealed underlying geological and cultural material and distributed objects by natural transport.

In our landscape survey, we are cognizant of the bias and skewing of the archaeological record due to both natural (as above) and anthropogenic (agricultural practices) processes. Although we collect artifacts during regular pedestrian survey, we are cautious about our interpretations of their distribution. Methodologically, we must rely heavily on high-resolution spatial patterning in order to isolate phenomena of legitimate archaeological interest. Likewise, we are aware that the pattern of archaeological sites and features is biased toward the hills and margins of the plain, where such phenomena are more readily visible than in the plain, where they may be covered. With these issues in mind, our survey intentionally incorporates varied topography, landforms, and vegetation each season in order to maintain consistent coverage and systematic sampling. By systematically collecting data at high spatial resolution, we aim to test the general assumptions about spatial bias as an important byproduct of our study of archaeology in this landscape. Below we summarize some of the important methodological innovations that facilitate a robust geospatial dataset in our work.

\section{DOCUMENTING TERRAIN AND FEATURES THROUGH REMOTE SENSING}

Our fieldwork aims to integrate two major forms of geospatial datasets, namely raster and vector data. A critical starting point is the ability to visualize the valley through maps and aerial imagery, which allows us to categorize the landscape and inform our sampling strategy on the ground. Initially, we relied on freely available imagery from archival maps, Google Earth, SRTM digital elevation models, and others to begin to understand the valley and its terrain. In order to increase our spatial resolution, we subsequently acquired $12-\mathrm{cm}$ resolution LiDAR and orthophoto coverage of the valley. Whereas these rich datasets allowed us to build terrain models and cross-reference features and land-use, we observed some major limitations. Once we began to incorporate our own vector data, which was derived from high resolution survey equipment, it was clear that the geospatial precision of our raster data proved to vary by a matter of a few meters. Furthermore, we were neither satisfied with the visual resolution of the images nor our lack of control over seasonality and other conditional variables in our datasets.

We therefore endeavored to implement our own data collection in the field by deploying an unmanned aerial vehicle (UAV or drone) ${ }^{2}$ to systematically collect aerial imagery at high spatial resolution, ca. $4 \mathrm{~cm}$ (Fig. 3). Even higher spatial resolutions are possible if the UAV is flown at lower altitudes. We applied a Structure from Motion (SfM) workflow originally developed for terrestrial images in excavation contexts ${ }^{\text {ii }}$ in order to produce dense point clouds, digital elevation models (DEMs), orthophotos, and textured 3D models on a landscape scale (Fig. 4). Although the GPS onboard the UAV produced georeferencing of comparable imprecision to the datasets mentioned above (ca. 3-5 m), by using ground control

\footnotetext{
${ }^{2}$ Our primary UAV is a DJI Inspire 1 RAW with a Zenmuse X5R RGB imaging sensor.
} 
points measured with a differential GPS or Total Station to georeference our models we achieve ca. $2-5 \mathrm{~cm}$ geospatial precision.

\section{Fig. 3: Flight plan and camera positions over Tel Abu Shusha}

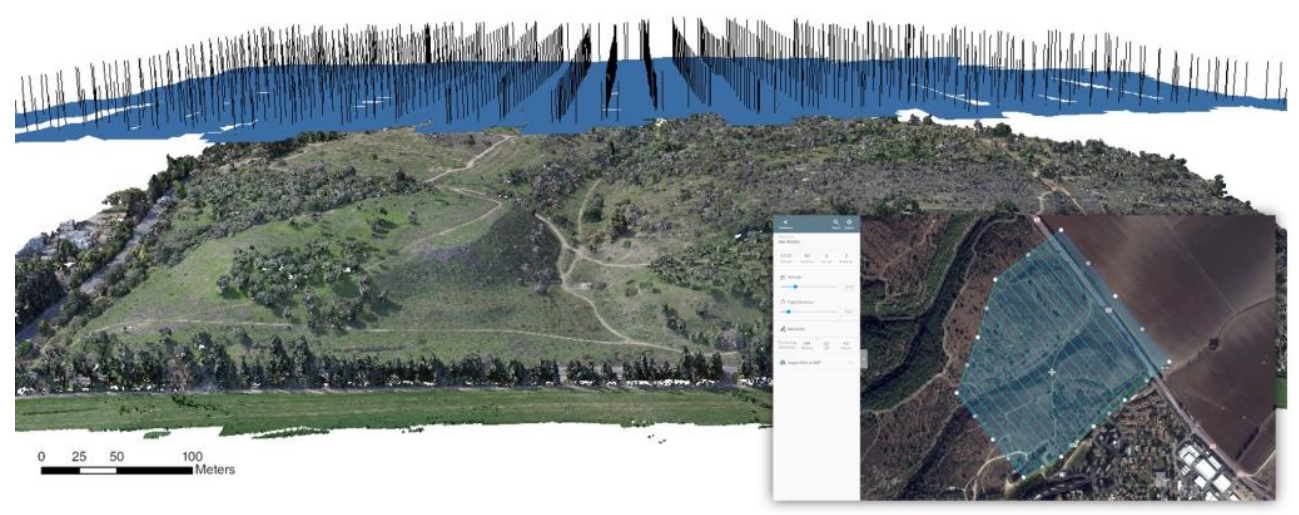

Fig. 4: Digital Elevation Model (DEM) and Orthophoto raster images of Tel Abu Shusha

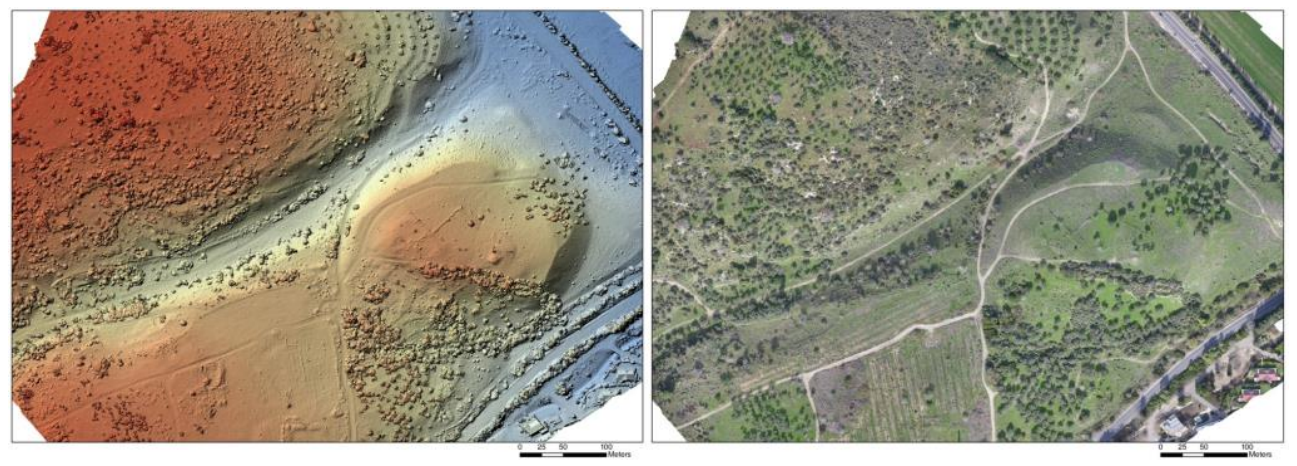

Not only did this method produce higher quality datasets than before, but it proved to be flexible and efficient enough to deploy on an iterative basis in order to document the exact conditions during field survey and return visits during different seasons. These innovations gave our project complete autonomy over data quality and acquisition. Furthermore, we are able to seamlessly integrate these landscape-scale datasets with higher resolution site- and feature-scale datasets, giving us multi-scaler raster data that are compatible with vector data generated from multiple devices during physical survey.

\section{Survey Methods ANd Data Collection}

The conceptual framework used to classify and quantify spatial units in our survey are as follows. The largest spatial unit is naturally the Jezreel Valley, in which all of our work is conducted. A Survey Region is a polygon encompassing all areas surveyed in a given season or visit. A Survey Area is polygon encompassing a discrete area of systematic survey and is further defined below. Within each Survey Area are loci, and each Locus is a single polyline 
segment representing a linear transect measuring ca. $100-150 \mathrm{~m}$, depending on coverage logistics. Individual surveyors walk in Locus transects spaced ca. $15 \mathrm{~m}$ apart and collect surface finds in their path. These finds are collected into Bags within each Locus that are classified by type of object (e.g., pottery, lithic). We consider these spatial entities to be arbitrarily defined by practical considerations such as physical characteristics and natural or artificial boundaries.

Survey Areas include: agricultural fields (by crop type), orchards, dirt roads, hilltops, hillslopes, and wadis (Fig. 5). Certain Survey Areas may not be accessible or feasible for physical survey due to vegetation conditions and/or agricultural processes (e.g., spraying insecticides or fertilizers, heavy irrigation, harvesting), but are documented nonetheless by basic descriptions and spatial extent. General descriptions are documented for every Survey Area, including: slope, soil color, soil texture, moisture, state of agricultural use, vegetation type, vegetation cover, surface visibility, geological notes, and major landforms. In so doing, we document variables that may impact the results of survey and remote sensing, while also compiling a detailed geographic description of the landscape.

\section{Fig. 5: Survey Areas from the 2016 Survey Season draped over a DTM and orthophoto, facing north}

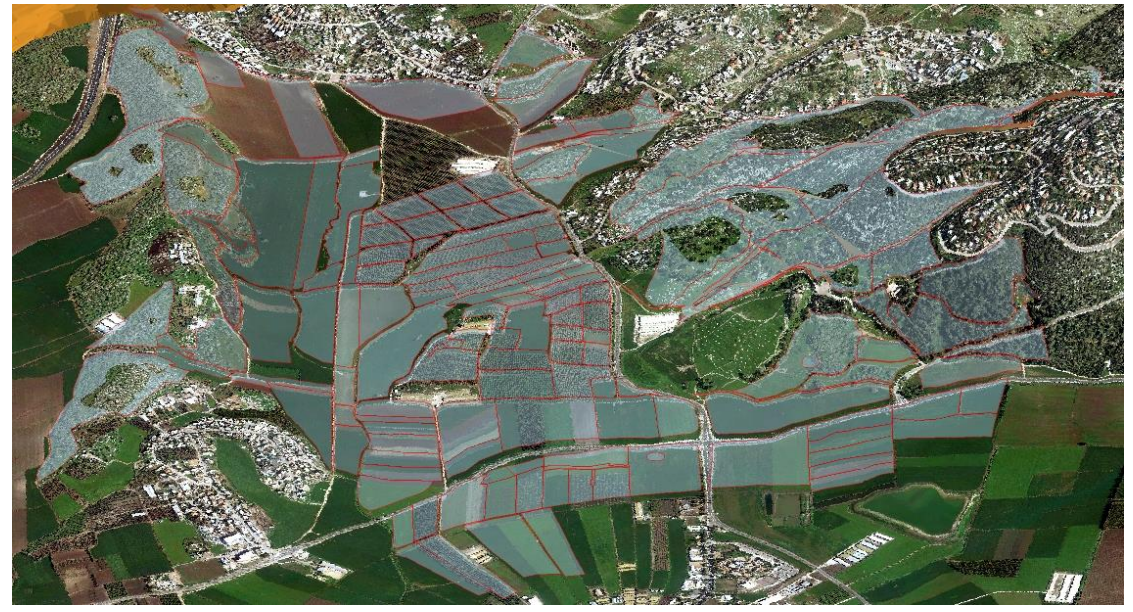

Non-arbitrary designations are given to real, non-portable phenomena and are termed Features. Features may include clear cultural activity (e.g., quarry, agricultural installation, burial, architectural element), including modern elements, or a natural locus of potential cultural activity (e.g., cave). Features are documented by classification and description, media (e.g., photos), and GPS points on multiple devices. A Site is a concentration of Features or finds. In our spatial hierarchy, Features and Sites are not contained within a Survey Area or Locus, but are rather associated with them.

Survey Areas, Loci, and Features are geospatially documented in real-time using the ESRI Collector for ArcGIS application operated on handheld iPad devices, which provides automatic and systematic generation of GIS shapefiles and feature classes. All data are recorded in our Codifi database ${ }^{3}$, also operated on iPad devices, including finds registration,

\footnotetext{
${ }^{3}$ Codifi is developed by the Center for Digital Archaeology, a US based 501(c)3 non-profit corporation, www.codifi.org.
} 
descriptions, notes, working photographs, and most geospatial data. These data are synchronized across devices and related to each other for immediate use in GIS applications, in which we associate our raster, vector, and attribute data for spatial analysis (Fig. 6).

Fig. 6: Vector data in GIS showing Survey Areas, Features, and Loci of the 2016 Survey Season (right), and in detail (left)
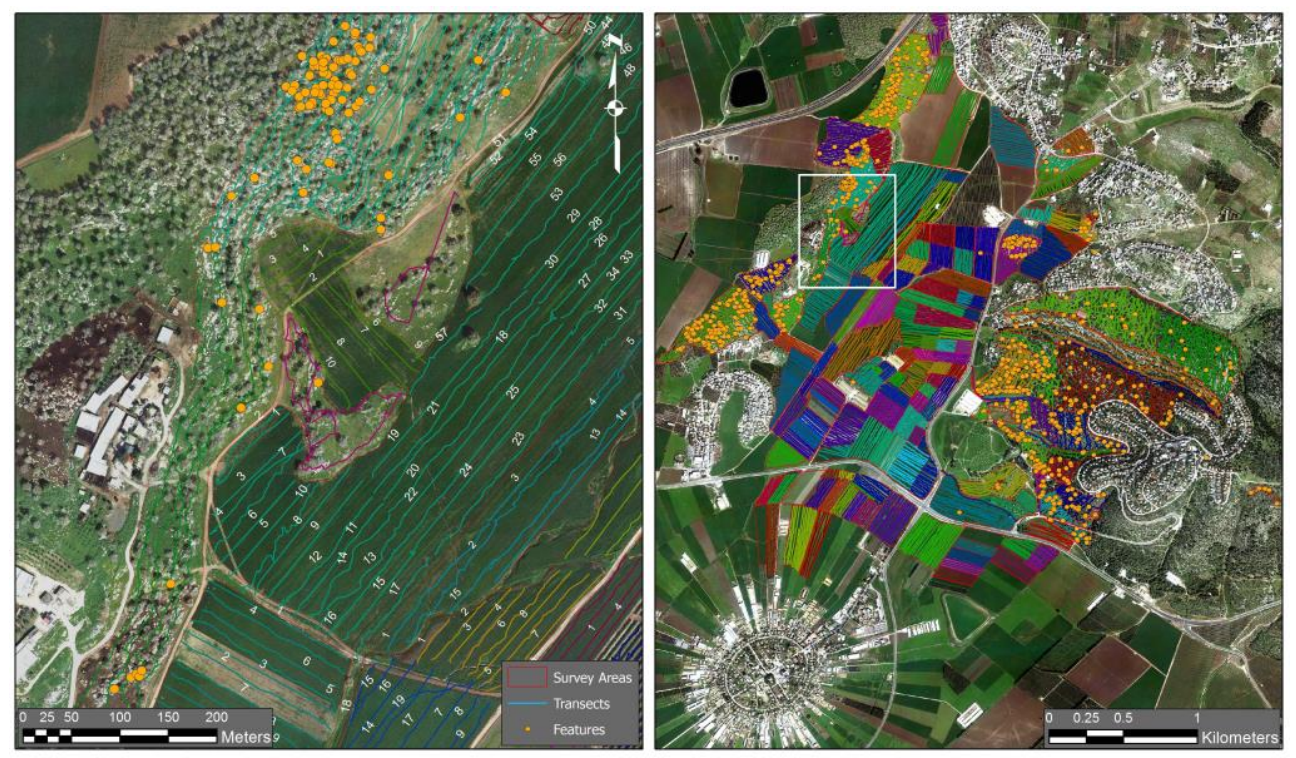

\section{OVERVIEW OF THE 2015 AND 2016 SURVEY SEASONS}

The areas investigated during the first two seasons of the JVRP Advanced Physical Survey were selected to include diverse topography, landforms, vegetation, and land-use in this are made it an ideal location to develop our field survey methods. The 2015 Survey Season was located along the west margin of the plain, and the 2016 Survey Season was located in the northeast margin of the plain, each representing slightly different conditions and landforms within the valley (Fig. 7).

The project's pilot survey season was conducted in 2015, in an area located ca. $2 \mathrm{~km}$ southeast of the Megiddo Junction (32.572736, 35.191701). This season covered an area of ca. $4 \mathrm{~km}^{2}$ of mixed terrain, including forested hills, agricultural fields, and one known archaeological site, Tel Qedesh. The western boundary was Highway 66, passing Giv'at Oz, and the southern boundary was the border fence of the West Bank, near the town of Zububa. In total, the 2015 season covered 91 Survey Areas, in which 2038 Features were documented (Fig. 8). In sum, the features fell into the following approximate categories (in order of frequency): cup marks, cuts and shafts, quarries, caves (including burials), miscellaneous installations of features, and presses (either wine or olive) (Fig. 9). 
Fig. 7: DTM of the Jezreel Valley based on $30 \mathrm{~m}$ SRTM data (NASA JPL 2013), with the 2015 and 2016 Survey Areas indicated in the southwest and northeast, respectively

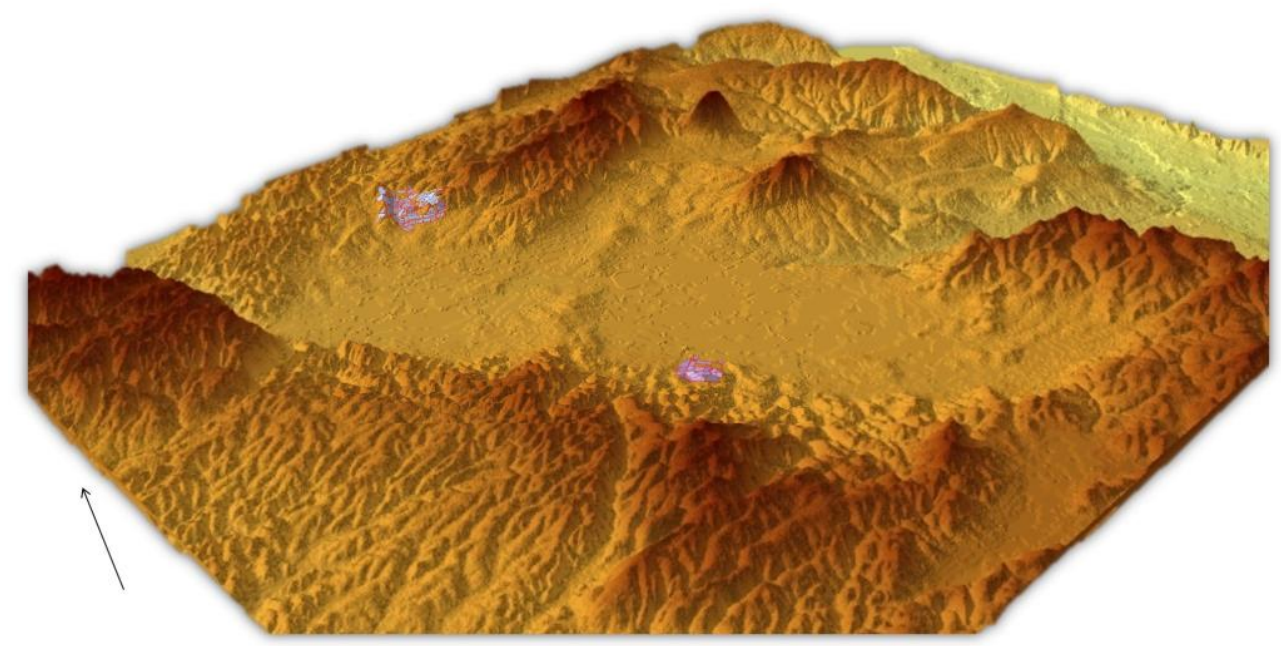

Fig. 8: 2015 Survey Areas and Features (left), and both 2015 and 2016 Survey Areas draped over the DTM (right)
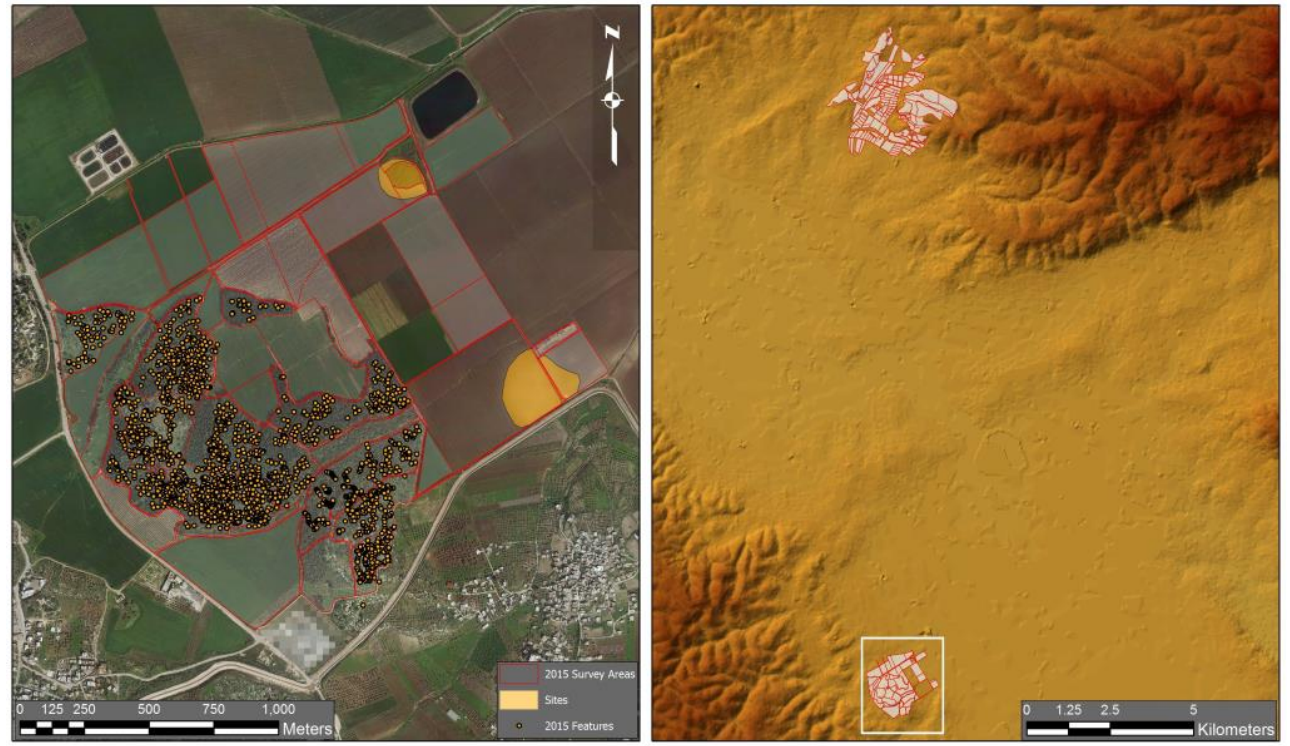
Fig. 9: An approximate breakdown of the types of features from the 2015 and 2016 Survey Seasons
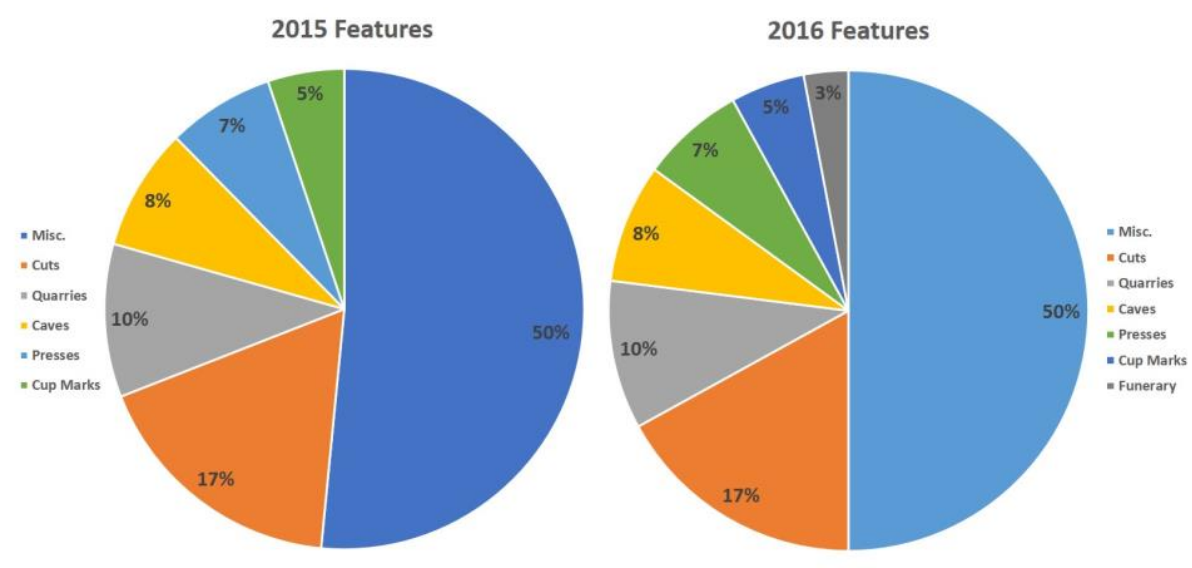

The area covered by the 2016 Survey Season was topographically and geographically confined by the broad wadi north of Nahalal $(32.690315,35.196470)$. In the north, the wadi comes to a narrow head at the towns comprising Zarzir, and widens to the south between Manshiyat al-Zabda (west) and Tel Shimron and the Nahalal Junction (east). The western boundary of survey was defined by the top of the limestone ridge extending from Manshiyat al-Zabda to Ghrifat (of Zarzir), whereas the eastern boundary was the top of the slopes settled by Iyadat and Mazarib (of Zarzir) and Timrat. Fields to the south of Highway 75 were surveyed up to the northern extent of the Nahalal settlement. Altogether, ca. $8 \mathrm{~km}^{2}$ of the landscape was covered by pedestrian survey, with mixed terrain including agricultural fields and orchards, uncultivated hillslopes, and the outer slopes of Tel Shimron.

The overall area was subdivided into 172 Survey Areas. The archaeological mound of Tel Shimron was not surveyed by our team, since it was concurrently being intensively surveyed by the site's excavation team. With a total of 2437 loci within the 172 survey areas, the spatial discrimination of finds was documented at a high resolution. A total of 1093 features were documented, almost entirely in the hills surrounding the wadi (Fig. 6). As in the 2015 Survey Season, more than $90 \%$ of these features were cut into the natural limestone bedrock, whereas the remainder were miscellaneous standing features. In sum, the features fell into the following approximate categories (in order of frequency): miscellaneous installations or features, cuts, quarries, caves, presses (olive or wine), cup marks, and funerary installations (Fig. 9).

Although pottery and lithic finds have only been preliminarily processed, we may permit a few general observations. Overall, the pottery from both survey seasons was predominantly Roman-Byzantine with a minor proportion of Bronze and Iron Age, and only some pre-Bronze Age and Medieval periods represented. One noteworthy pattern emerged from the 2016 Survey Season in Survey Areas to the west of Nahalal Junction, where a high proportion and concentration of Intermediate and Middle Bronze sherds were discovered (Fig. 10). This concentration of finds suggests a site measuring perhaps $300 \mathrm{~m}$ or more in diameter. However, apart from the concentration of pottery, no features were identified in this flat-lying area. 
Fig. 10: Spatial distribution and proportion of Middle Bronze pottery conveyed by modified GIS hotspot analysis. Minimum threshold for visualized instance (bag): > $50 \%$ Middle Bronze by proportion, > 30 sherd count
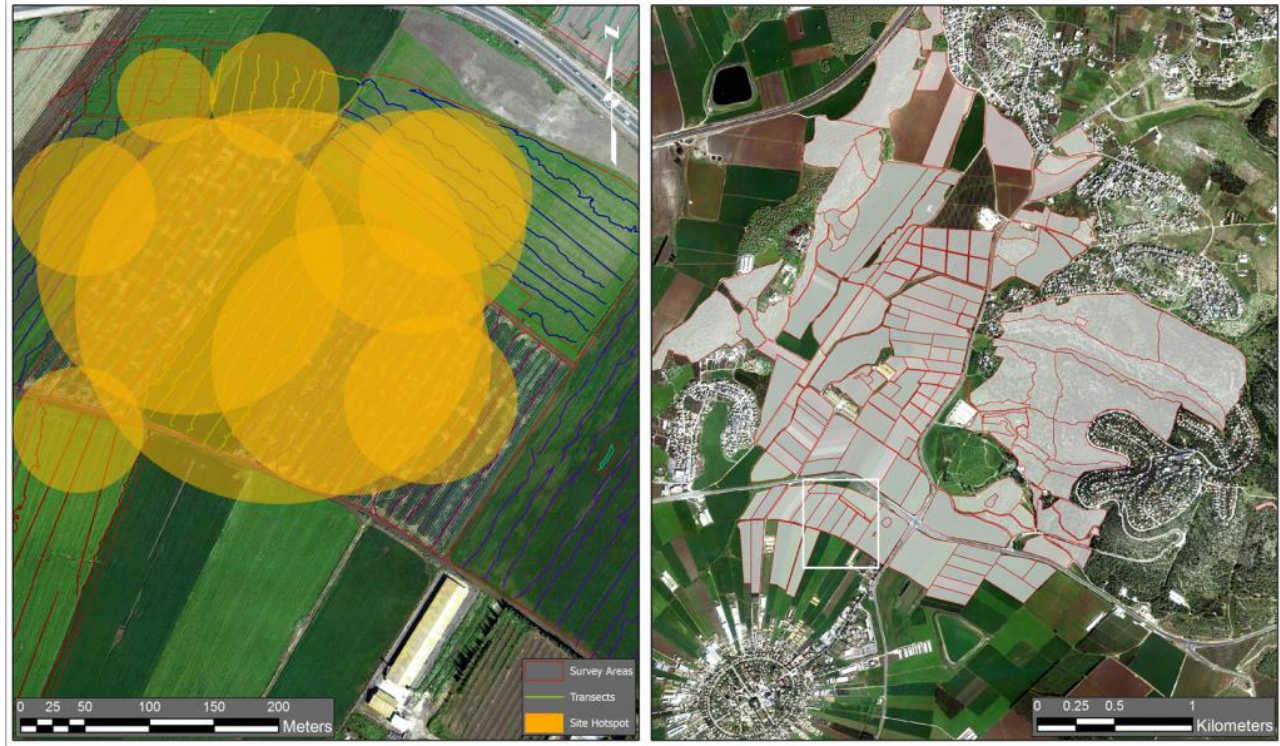

The 2016 flint assemblage was quite abundant and covered a span of different periods. In particular, there was a major pattern of lithic concentration in the center of the wadi, near the main modern drainage channel. In these Survey Areas, a high proportion of Middle Paleolithic finds were collected (R. Shimelmitz, pers. communication). These objects were in a good state of morphological preservation, suggesting that they were not transported very far away from their primary context (if, indeed, they are in secondary deposits). In summary, preliminary findings indicate that this area contains significant remains dating to the Middle Paleolithic period, which has not been extensively documented in this region.

Several features (i.e., caves) documented in the hills may be important loci for further investigation. Likewise, further spatial analysis from the current dataset and study of the finds may yield important patterns of artifact distribution. Features and pottery indicate agricultural and settlement activity during the Bronze Age, particularly the Middle Bronze, very little Iron Age, and a considerable amount of activity during the Roman to Byzantine Period. Additional study of the material and its integration into spatial analysis will provide more detailed results to follow in a final report.

\section{SUMMARY}

Although the results presented here are at a preliminary stage of research, the new digital geospatial methods being employed by the JVRP demonstrate an unprecedented potential for high-resolution archaeological and environmental study of the landscape of the Jezreel Valley. Our conceptual approach to geographic space and the geospatial tools we deploy in the field allow us to collect an incredible quantity of high-resolution data in an efficient workflow. Moreover, we exercise due caution regarding the dynamic changes in the environment over time that may obscure or skew the archaeological dataset on which we rely 
so strongly. By integrating archaeological survey and excavation with environmental datasets, geospatial precision, and comprehensive data collection we may begin to abandon the paradigm of simply hunting for major archaeological sites, instead focusing on the complex relationship between humans and their landscape through time.

\section{REFERENCES}

Adams, M.J., David, J., Homsher, R. \& Cohen, M.E. (2014). New Evidence for the Rise of a Complex Society in the Late Fourth Millennium at Tel Megiddo East in the Jezreel Valley. Near Eastern Archaeology, 77(1), 32-43.

Adams, M.J., Homsher, R.S. \& Cohen, M.E. (Eds.), (Forthcoming). Tel Megiddo East 1 (2010-2013 Seasons). Jezreel Valley Regional Project Studies 1. Atlanta: Lockwood Press.

Horowitz, A. (1979). The Quaternary of Israel. New York: Academic.

NASA JPL. (2013). NASA Shuttle Radar Topography Mission Global 1 arc second [Data set]. NASA LP DAAC. Retrieved November 1, 2016, from: https://doi.org/ 10.5067/MEaSUREs/SRTM/SRTMGL1.003

Orni, E. \& Efrat, E. (1964). Geography of Israel. Jerusalem: Israel Program for Scientific Translations.

Prins, A.B. (2016). 3D Modeling for Archaeological Documentation: using the JVRP Method to record archaeological excavations with millimeter-accuracy. JVRP White Papers in Archaeological Technology, Jezreel Valley Regional Project website. Version 3.0. Retrieved September 18, 2016, from: http://jezreelvalleyregionalproject.com/ Prins-2016_3D-Modeling-for-Archaeological-Documentation_Version-3.0.pdf.

Rosen, A.M. (2006). Climate Change, Landscape and Shifting Agricultural Potential. In I. Finkelstein, D. Ussishkin \& B. Halpern (Eds.), Megiddo IV: The 1998-2002 Seasons. (pp. 463-70). Tel Aviv: Emery Claire Yass Publications in Archaeology.

\footnotetext{
${ }^{\text {i }}$ See Adams et al. (2014; forthcoming) for more information regarding the environmental study of the Megiddo environs.

ii See Prins (2016) for details on our Structure from Motion workflow.
} 